\title{
Treatment options for hypertension in high-risk patients
}

This article was published in the following Dove Press journal:

Vascular Health and Risk Management

8 March 201I

Number of times this article has been viewed

\section{Wei-Chuan Tsai}

Department of Internal Medicine, National Cheng Kung University Hospital, Tainan, Taiwan
Correspondence: Wei-Chuan Tsai Department of Internal Medicine, National Cheng Kung University Hospital and Medical College,

I 38 Sheng-Li Road,

Tainan 704, Taiwan

Tel +88662353535

Fax +886 62099578

Email wctsai@ksmail.seed.net.tw
Abstract: Patients are considered to be at high risk of cardiovascular events if they have diabetes, chronic kidney disease, stroke, established coronary artery disease, or a coronary artery disease equivalent. Blood pressure-lowering therapy has been shown to reduce cardiovascular events in these patients significantly. Identification of high-risk patients by global risk evaluation is recommended for every hypertensive patient. Treatment of hypertension in high-risk patients with an angiotensin-converting enzyme inhibitor or an angiotensin receptor antagonist, with or without addition of a dihydropyridine calcium channel antagonist, is a reasonable approach based on current clinical trials.

Keywords: hypertension, high-risk, antihypertensive agent

\section{Introduction}

Cardiovascular disease is an important cause of death worldwide. Hypertension is one of the major risk factors and is correlated with a risk of stroke, coronary artery disease, peripheral vascular disease, heart failure, and renal disease. ${ }^{1,2}$ Together with other risk factors, including diabetes mellitus, dyslipidemia, smoking, and obesity, hypertension significantly contributes to the global cardiovascular burden of morbidity and mortality, as well as increasing individual absolute cardiovascular risk. ${ }^{3}$

Identifying and treating risk factors in patients at high risk of cardiovascular events can significantly reduce the risk. ${ }^{4}$ Patients are considered to be at high risk if they have diabetes, chronic kidney disease, stroke, established coronary artery disease, or a coronary artery disease equivalent, including carotid artery disease, peripheral arterial disease, and abdominal aneurysm. ${ }^{1}$ Blood pressure-lowering therapy has been shown to reduce cardiovascular events in these patients significantly. ${ }^{5}$ Successful prevention of cardiovascular events in high-risk patients requires identification of patients at risk and comprehensive risk factor management, including treatment of hypertension.

\section{Identification of high-risk patients}

The risk of a cardiovascular event increases dramatically when a hypertensive patient has vascular disease, including coronary artery disease, cerebrovascular disease, and peripheral vascular disease. ${ }^{1,4,6}$ In patients with diabetes mellitus, up to $65 \%$ of deaths are due to coronary artery disease and/or stroke, and diabetes mellitus has been considered as a coronary disease equivalent. ${ }^{4,7}$ Clustering of risk factors increases the risk of cardiovascular events. The Multiple Risk Factor Intervention 
Trial demonstrated that cardiovascular mortality increases significantly when the number of risk factors accumulates. ${ }^{8}$ The presence of left ventricular hypertrophy has also been shown to increase the risk of cardiovascular events in hypertension significantly. ${ }^{9}$

Total cardiovascular risk assessment is recommended during the initial evaluation of all hypertensive patients. ${ }^{10}$ Factors influencing prognosis include blood pressure levels, other cardiovascular risk factors, diabetes mellitus or metabolic syndrome, subclinical organ damage, and established vascular or renal disease. ${ }^{10} \mathrm{~A}$ summary of highrisk conditions is listed in Table 1.

\section{Major trials in high-risk patients}

Many clinical trials have investigated the effects of reducing cardiovascular risk in the treatment of hypertension. These large, randomized, controlled trials provide clinical evidence and have implications for the treatment of hypertension in high-risk patients (Table 2). ${ }^{11-17}$

The Heart Outcomes Prevention Evaluation study demonstrated that the angiotensin-converting enzyme inhibitor, ramipril, could significantly reduce primary endpoints (myocardial infarction, stroke, cardiovascular death) in high-risk patients. ${ }^{11}$ The Losartan Intervention For Endpoint reduction in hypertension study compared the angiotensin receptor antagonist, losartan, with the beta-blocker, atenolol, in patients with left ventricular hypertrophy. The degree of left ventricular hypertrophy regression and primary endpoints (myocardial infarction, stroke, cardiovascular death) were significantly improved in the losartan group than in the atenolol group. ${ }^{12}$ The AngloScandinavian Cardiac Outcome Trial - Blood Pressure Lowering Arm compared amlodipine-based (with or without an angiotensin-converting enzyme inhibitor) and atenololbased (with or without a thiazide diuretic) treatment in

Table I High risk conditions in hypertension*

Systolic blood pressure $\geq 180 \mathrm{mmHg}$ and/or diastolic

blood pressure $\geq 110 \mathrm{mmHg}$

Diabetes mellitus

Metabolic syndrome

Three or more cardiovascular risk factors

One or more manifestations of subclinical organ damage, eg, left

ventricular hypertrophy

Established coronary artery disease

Established cerebrovascular disease

Established peripheral vascular disease

Established chronic kidney disease

Note: *Adapted from the 2007 European Society of Hypertension and the European Society of Cardiology guidelines for the treatment of arterial hypertension. ${ }^{10}$ hypertensive patients with three or more study-specified risk factors. This study did not show any differences in the primary endpoints (nonfatal myocardial infarction and fatal coronary artery disease), but did show a significantly reduced number of overall cardiovascular events (hazard ratio [HR] $0.84,95 \%$ confidence interval $0.78-0.90, P<0.0001$ ) in the amlodipine-based treatment group. ${ }^{13}$ The Action in Diabetes and Vascular Disease: Preterax and Diamicron-Controlled Evaluation Trial included patients with Type 2 diabetes mellitus and assessed the effects of the combination of the angiotensin-converting enzyme inhibitor, perindopril, and a diuretic, indapamide, on vascular events. The primary endpoints (macrovascular and microvascular events) were significantly reduced in the active treatment group (relative risk reduction $9 \%, P=0.04$ ). All cause mortality (HR 0.86 , $P=0.03)$ and coronary events (HR $0.86, P=0.02$ ) were also significantly reduced in the active treatment group. ${ }^{14}$ The Ongoing Telmisartan Alone and in Combination With Ramipril Global Endpoint Trial (ONTARGET) study involved high-risk patients with coronary, peripheral arterial, or cerebrovascular disease, and diabetic patients with target organ damage. The patients were randomized into ramipril, telmisartan, and ramipril + telmisartan groups. The primary endpoints (the composite of cardiovascular death, myocardial infarction, stroke, or hospitalization for heart failure) were similar in these groups. However, more hypotension and renal dysfunction were noted in the combination group. ${ }^{15}$ The Telmisartan Randomized Assessment Study in ACE Intolerant Subjects With Cardiovascular Disease study included patients who were screened for the ONTARGET study but were unable to tolerate angiotensin-converting enzyme inhibitors. The primary composite outcome was the same as for the ONTARGET study, and occurred in $15.7 \%$ of the telmisartan patients and $17.0 \%$ of the placebo patients $(P=0.22)$. However, the telmisartan group had significantly lower composite secondary outcomes $(P=0.048) .{ }^{16}$ The Avoiding Cardiovascular Events Through Combination Therapy in Patients Living With Systolic Hypertension study tested whether treatment with the combination of an angiotensin-converting enzyme inhibitor and a dihydropyridine calcium channel blocker was more effective than combination with a thiazide in cardiovascular event reduction. The primary outcome (the composite of death from cardiovascular causes, nonfatal myocardial infarction, nonfatal stroke, hospitalization for angina, resuscitation after sudden cardiac arrest, and coronary revascularization) was significantly lower in the benazepril + amlodipine group than in the benazepril + hydrochlorothiazide group. ${ }^{17}$ 


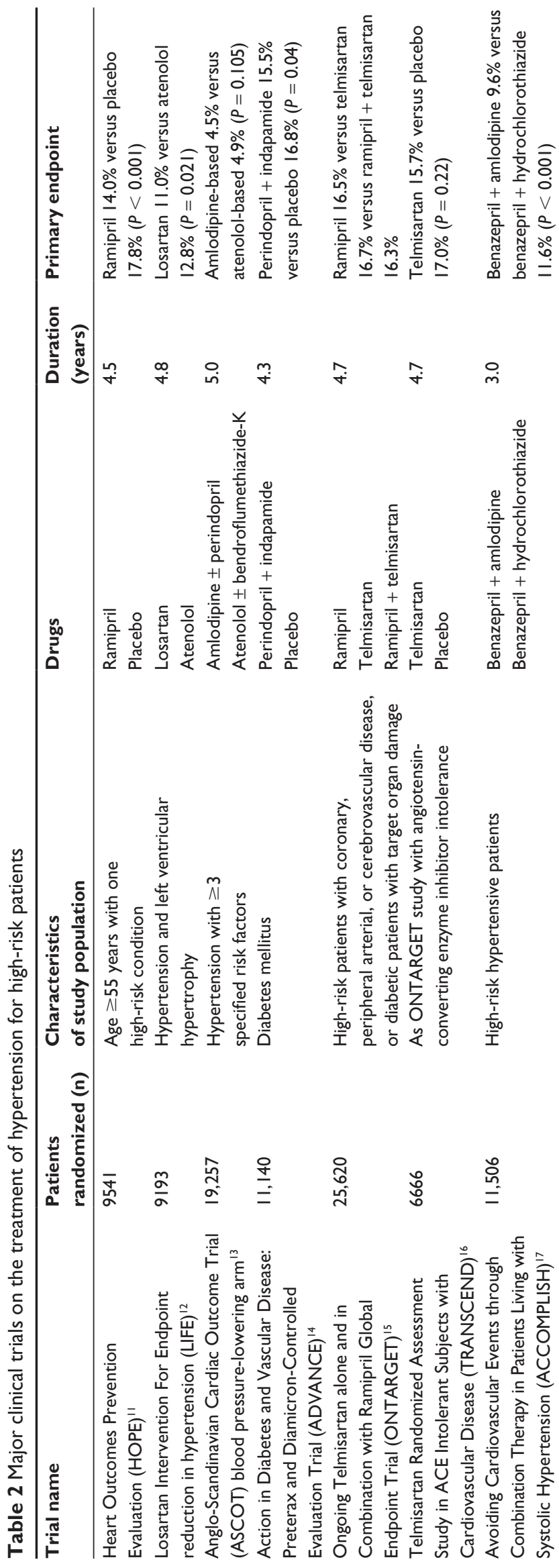

From the results of these trials, it is reasonable to recommend using an angiotensin-converting enzyme inhibitor or angiotensin receptor blocker for the treatment of hypertension in high-risk patients. The combination of an angiotensin-converting enzyme inhibitor or angiotensin receptor blocker with a dihydropyridine calcium channel blocker was also shown to be beneficial in the treatment of high-risk patients. However, the combination of an angiotensin-converting enzyme inhibitor with an angiotensin receptor blocker should only be used sparingly and very carefully in patients at high risk based on the currently available evidence. ${ }^{18}$

\section{Level and speed of blood pressure- lowering in high-risk patients}

Most of the hypertension treatment guidelines recommend a blood pressure target of $<130 / 80 \mathrm{mmHg}$ for high-risk patients. ${ }^{1,9,10}$ Critical analyses of the results of available trials show that the evidence is scanty for this recommendation. ${ }^{19}$ Most of the clinical trials did not reach this blood pressure target when treating-high risk patients, and the recommendation is based more on assumptions than on hard evidence. ${ }^{19}$ The Action to Control Cardiovascular Risk in Diabetes blood pressure trial demonstrated that targeting a systolic blood pressure of $<120 \mathrm{mmHg}$ as compared with $<140 \mathrm{mmHg}$ did not reduce cardiovascular risk in high-risk diabetes patients. ${ }^{20}$ Further studies are needed to confirm the ideal blood pressure target for high-risk patients. Nonetheless, all observations indicate that aiming at a lower blood pressure target of $130 \mathrm{mmHg}$ does not increase risk and is well tolerated. ${ }^{19}$ Therefore, it is acceptable currently to advise targeting a systolic blood pressure of $130 \mathrm{mmHg}$ in clinical practice.

There is no doubt that antihypertensive medication should be initiated immediately in high or very high-risk hypertensive patients. ${ }^{10}$ The concept of "sooner is better" is important for high-risk patients based on the Valsartan Antihypertensive Long-term Use Evaluation (VALUE) trial. ${ }^{21}$ The VALUE trial showed that a greater blood pressure reduction in the first six months in the amlodipine group was associated with a lower cardiovascular event rate than in the valsartan group. ${ }^{21}$

\section{Role of direct renin inhibitors in high-risk patients}

The direct renin inhibitor, aliskiren, has recently been developed for the treatment of hypertension. Based on the successful results of previous studies regarding the protective 
effects of blocking the renin-angiotensin-aldosterone system by angiotensin-converting enzyme inhibitors or angiotensinreceptor blockers in high-risk patients, direct renin inhibitors have attracted interest due to their protective effects in high-risk patients. Direct renin inhibitors block the reninangiotensin-aldosterone system at its point of origin, and also decrease plasma renin activity by blocking renin or prorenin receptors and eliminating the adverse effects of renin or prorenin receptor activation. ${ }^{22}$ Some studies of organ protective effects have shown comparative or even better results with angiotensin-converting enzyme inhibitors or angiotensin receptor blockers when a direct renin inhibitor was used as monotherapy or in combination with other renin-angiotensin-aldosterone system inhibitors. ${ }^{23}$ The organ protective effect of direct renin inhibitors has been shown to be more pronounced for the kidney. ${ }^{24}$ Direct renin inhibitors showed a good and rapid blood pressure-lowering response when used in combination with a calcium channel antagonist in a recently published hypertension study. ${ }^{25}$ Used alone or in combination, direct renin inhibitors have great potential in the treatment of hypertension in high-risk patients. However, results of large randomized controlled studies for the major cardiovascular endpoints are needed to define their role in high-risk patients.

\section{Conclusion}

Treatment of hypertension in high-risk patients can reduce cardiovascular events. Identification of high-risk patients by global risk evaluation is recommended for every hypertensive patient. Treatment of hypertension in high-risk patients with an angiotensin-converting enzyme inhibitor or an angiotensin receptor antagonist, with or without addition of a dihydropyridine calcium channel blocker, is a reasonable approach based on current clinical trial evidence.

\section{Disclosure}

The author reports no conflict of interest in this work.

\section{References}

1. Chiang CE, Wang TD, Li YH, et al. 2010 Guideline of the Taiwan Society of Cardiology for the management of hypertension. $J$ Formos Med Assoc. 2010;109:740-773.

2. Lewington S, Clarke R, Qizilbash N, et al. Age-specific relevance of usual blood pressure to vascular mortality: A meta-analysis of individual data for one million adults in 61 prospective studies. Lancet. 2002; 360:1903-1913.

3. Kannel WB. Risk stratification in hypertension: New insight from the Framingham Study. Am J Hypertens. 2000;13(1 Pt 2):S3-S10.
4. Deedwania P. Evolving treatment options for prevention of cardiovascular events in high-risk hypertensive patients. J Clin Hypertens. 2007; 9:883-888.

5. Neal B, MacMahon S, Chapman N. Effects of ACE inhibitors, calcium antagonists, and other blood-pressure-lowering drugs: Results of prospectively designed overviews of randomized trials. Blood Pressure Lowering Treatment Trialists' Collaboration. Lancet. 2000;42: $1206-1252$.

6. Kannel WB. Hazards, risks, and threats of heart disease from the early stages to symptomatic coronary heart disease and cardiac failure. Cardiovasc Drugs Ther. 1997;11 Suppl 1:199-212.

7. Kempler P. Learning from large cardiovascular clinical trials: Classical cardiovascular risk factors. Diabetes Res Clin Pract. 2005;68 Suppl 1: S43-S47.

8. Stamler J, Vaccaro O, Neaton JD, et al. Diabetes, other risk factors, and 12-year cardiovascular mortality for men screened in the Multiple Risk Factor Intervention Trial. Diabetes Care. 1993;16:434-444.

9. Chobanian AV, Bakris JL, Black HR, et al. The Seventh Report of the Joint National Committee on Prevention, Detection, and Treatment of High Blood Pressure: The JNC 7 Report. JAMA. 2003;289: 2560-2571.

10. Mancia G, De Backer G, Dominiczak A, et al. 2007 ESH-ESC Guideline for the management of arterial hypertension. Blood Press. 2007;16: $135-132$.

11. The Heart Outcomes Prevention Evaluation Study Investigators. Effects of an angiotensin-concerting-enzyme inhibitor, ramipril, on cardiovascular events in high-risk patients. $N$ Engl J Med. 2000;342: 145-153.

12. Dahlof B, Devereux RB, Kjeldsen SE, et al. Cardiovascular morbidity and mortality in the Losartan Intervention For Endpoint reduction in hypertension study (LIFE): A randomized trial against atenolol. Lancet. 2002;359:995-1003.

13. Dahlof B, Sever PS, Poulter NR, et al. Prevention of cardiovascular events with an antihypertensive regimen of amlodipine adding perindopril as required versus atenolol adding bendroflumethiazide as required, in the Anglo-Scandinavian Cardiac Outcome Trial-Blood Pressure Lowering Arm (ASCOT-BPLA): A multicenter randomized controlled trial. Lancet. 2005;366:895-906.

14. ADVANCE Collaborative Group. Effects of a fixed combination of perindopril and indapamide on macrovascular and microvascular outcomes in patients with type 2 diabetes mellitus (the ADVANCE Trial): A randomized controlled trial. Lancet. 2007;370:829-840.

15. The ONTARGET Investigators. Telmisartan, ramipril, or both in patients at high risk for vascular events. $N$ Engl J Med. 2008;358: $1547-1559$.

16. The TRANSCEND Investigators. Effects of the angiotensin-receptor blocker telmisartan on cardiovascular events in high-risk patients intolerant to angiotensin-converting enzyme inhibitors: A randomized controlled trial. Lancet. 2008;372:1174-1183.

17. The ACCOMPLISH Trial Investigators. Benazapril plus amlodipine or hydrochlorothiazide for hypertension in high-risk patients. $N$ Engl J Med. 2008;359:2417-2428.

18. Staessen JA, Richart T, Wang Z, et al. Implications of recently published trials of blood pressure lowering drugs in hypertensive or high-risk patients. Hypertension. 2010;55:819-831.

19. Zanchetti A, Grassi G, Mancia G. When should antihypertensive drug treatment be initiated and to what levels should systolic blood pressure be lowered? A critical reappraisal. J Hypertens. 2009;27: 923-934.

20. The ACCORD Study Investigators. Effects of intensive blood-pressure control in type 2 diabetes mellitus. $N$ Engl J Med. 2010;362: $1575-1585$.

21. The VALUE Trial Investigators. Outcomes in hypertensive patients at high cardiovascular risk treated with regimens based on valsartan or amlodipine: The VALUE randomized trial. Lancet. 2004;363: 2022-2031. 
22. Gaddam KK, Oparil S. Renin inhibition: Should it supplant ACE inhibitors and ARBS in high risk patients? Curr Opin Nephrol Hypertens. 2008;17:484-490.

23. Cagnoni F, Njwe CAN, Zaninelli A, et al. Blocking the RAAS at different levels: An update on the use of the direct renin inhibitors alone or in combination. Vasc Health Risk Manage. 2010;6:549-559.

24. Feldman DL. New insights into the renoprotective actions of the renin inhibitor aliskiren in experimental renal disease. Hypertens Res. 2010; 33:279-287.
25. Brown MJ, McInnes GT, Papst CC, et al. Aliskiren and the calcium channel blocker amlodipine combination as an initial treatment strategy for hypertension control (ACCELERATE): A randomized, parallel-group trial. Lancet. 2011;377:312-320.

\section{Publish your work in this journal}

Vascular Health and Risk Management is an international, peerreviewed journal of therapeutics and risk management, focusing on concise rapid reporting of clinical studies on the processes involved in the maintenance of vascular health; the monitoring, prevention and treatment of vascular disease and its sequelae; and the involvement of metabolic disorders, particularly diabetes. This journal is indexed on PubMed Central and MedLine. The manuscript management system is completely online and includes a very quick and fair peer-review system, which is all easy to use. Visit http://www.dovepress.com/ testimonials.php to read real quotes from published authors.

Submit your manuscript here: http://www.dovepress.com/vascular-health-and-risk-management-journal 